\title{
Eco-Environmental Quality Assessment of Xining City Based on GIS and AHP
}

\author{
Zhang Liqian \\ Institute of Geographic Sciences and Natural Resources Research \\ Chinese Academy of Science, Beijing 100101, China \\ $\&$ \\ Graduate Institute of Chinese Academy of Sciences, Beijing 100101, China \\ Cai Jianming \\ Institute of Geographic Sciences and Natural Resources Research \\ Chinese Academy of Science, Beijing 100101, China
}

Received: October 31, 2011

Accepted: February 28, $2012 \quad$ Published: April 1, 2012

doi:10.5539/mas.v6n4p84

URL: http://dx.doi.org/10.5539/mas.v6n4p84

\begin{abstract}
This paper studies the Analytic Hierarchy Process (AHP), and puts forward the ecological environment AHP index of Xining City accordingly. By using GIS technology, Five-Laps-linkage Thought and Traffic Lights Principle, the writer makes a qualitative and quantitative analysis of Eco-environmental Quality, and gives an accurate and objective assessment to the Eco-environmental Quality of Xining City. These assessments would help a lot for government to determine the ecological environment protection policies. Studies show that, social circle, hydrosphere, atmosphere, lithosphere and biosphere make a decline in turn influence to Xining Eco-environmental Quality assessment, and hence the mean, social circle is the strongest influence to Xining Eco-environmental Quality. For a long time, the ecological environment in this area is in a precarious position; as a result, we should prevent to make aggressive decision during the urbanization, value the quality instead of quantity. Focus on the development of eco-industries; and gradually improve the Eco-environmental Quality in some area where is not so good; using the coordinative development principle between resources, environment and economy to guide regional urbanization.
\end{abstract}

Keywords: Analytic Hierarchy Process (AHP), Eco-environmental Quality, Xining City, GIS

\section{Foreword}

Eco-environmental Quality means the strength and weakness of ecological environment. Based on the ecology theory, it reflects the ecological environment suitability to human existence and socio-economic sustainable development. So it is reasonable to assess its quality and state according to human specific requirements. Eco-environmental Quality assessment is assessing regional eco-environmental quality according to chosen index system and using the method of comprehensive evaluation to assess the pros and cons of regional ecological environment (Hai \& Wang, 2004). No matter as the eco-environment situation and environment influence assessment reference standard, or as the environment planning and development basic foundation, the eco-environment assessment would play a very important role. From the original descriptive assessment of regional nature and social economy in traditional geography, to today's comprehensive assessment involves various ecological factors and different scales, there is still lack of standard and generally accepted theoretical framework, index system and ways of assessment (Li, et al., 2009; Li, et al., 2009; Jin, et al., 1992; Wu, 2000). In recent years, AHP is using more and more frequently in the Eco-environment assessment field. Although GIS and city eco-environment are belonging to different field, they have the common space concept, so they can be combined organically (Huang, Wang \& Yang, 2009). This paper assessed the eco-environmental quality in Xining city mainly by using GIS technology and AHP system.

In this study, the writer adopt the Five-laps-linkage Thought, say, lithosphere, hydrosphere, atmosphere, biosphere and social circle five laps influence and interact to each other, and they made up the ecological 
environment together. From the inspiration of traffic lights, the writer marks the assessment result with colors, which shows the qualities-red for stop, green for pass-the more the color tends to red, the worse the quality is.

\section{Study Area and Research Method}

\subsection{The General Situation of Study Area}

The study area of this paper including five districts and three counties of Xining city, its geographical position is between the longitude $100^{\circ} 54^{\prime} \sim 101^{\circ} 55^{\prime}$ and latitude $36^{\circ} 13^{\prime} \sim 37^{\circ} 25^{\prime}$, city center position is east longitude $101^{\circ} 46$ and north latitude $36^{\circ} 37^{\prime}$, elevation 2261.2 meters. Land area covers $737967.02 \mathrm{hm}^{2}$, accounting for about $1 \%$ area of the province, and population in this area accounting for $45.67 \%$, that's to say this area has a high degree of urban primacy ratio. Huangshui River is running throughout the city from west to the east, during which different tributaries afflux into it from north or south. This makes this area a mountainous terrain with rivers and hills. Xining is located in the eastern edge of the Qinghai-Tibetan plateau, in valley of Huangshui River-which is a tributary if Yellow River, on the boundary of Qinghai-Tibet Plateau and Loess Plateau. This special geographic position enables Xining become a gate for Qinghai-Tibet Plateau to communicate with outer area. This city is the transportation hub of Qinghai province and material distributing centre of the plateau, and what's more, Xining is also the core city of China's West Development Policy. The average elevation of Qinghai-Tibet Plateau is 4000 meters above; it is unfavorable for human living because of depression and lack of oxygen. Related research shows that, the 3000 meters is the critical height for plateau stress. But Xining's elevation is about 2200 meters and is the only one big city on the Qinghai-Tibet Plateau which is below the critical value, with unique superior livable condition in this region.

\subsection{Research Methods}

Analytical Hierarchy Process (AHP), was introduced by the American operations researcher A. L. Saaty in the 1970 s, is a kind of qualitative and quantitative decision analysis method. It makes a policymaker's thinking process to complex system more modeling and quantitative. By using these methods, the policymakers firstly decompose the complex issue to certain gradations and factors, and then make a simple comparison and calculation between factors, so they can get target weight of different program. These target weight can provide policymakers to choose the best program. The characteristic of this method is providing simple evaluation methods for complex problems by using less quantitative information, on the basis of deeply research of complex problems' nature, influence factor and internal relationship. At the same time, it is also an effectively multi-object evaluation method; it makes all the evaluation and planning problems in orderly hierarchical structure, and then put the programs in order by judging their value, and finds the best one. This process make comprehensive sort after weighting operation to original observed numbers, so it will not weaken the original information, not only quantizes the assessment index logic, but also keep the consistency during the whole determination. Thus, this method solely applies for eco-environmental quality assessment.

This paper is trying to evaluate the Eco-environmental quality by using AHP method. Eco-environment assessment is the standard to evaluate the whole regional Eco-environment condition, or to determine the good from bad of some regional comprehensive development and construction. For providing the basis for decision-making of regional eco-environment planning and Eco-environment problems, this study evaluates Eco-environment according to the Eco-environment of sub areas. To make an assessment for every single plate is the most basic evaluation and analysis target.

\section{Establishment of Evaluation Index System}

Eco-environmental quality evaluation index system is based on reasonable and evaluation criteria, using appropriate methods to evaluate the ecological quality of the pros and cons of the geological environment. No matter what type of assessment we adopt, establish a scientific, improved and feasible index system, and choose an appropriate evaluation standard is the key of a successful eco-environmental quality assessment. Reasonable and appropriate index selection is one of the top priorities in eco-environmental quality assessment.

\subsection{The Principle of Index Selection}

In the eco-environmental quality assessment, the chosen index must characterize the features of the eco-system in study area, that's to say, it has to be representative and typical. On the other hand, the chosen indicators should be based on realistic data access to the resources. In general, the index selection of ecological and geological environment quality assessment should follow the following principles:

(1) Representative: to reflect the essential characteristics of the ecological environment.

(2) Comprehensive: to reflect the characteristics of nature, ecology and society as reliable as possible. 
(3) Integrated: to reflect the characteristics both of holistic and comprehensive in environmental protection.

(4) Simple: index should be detailed as much as possible, while evaluation method should be simple as possible.

(5) Convenient: Index data should be accessible and easy to update.

(6) Applicable: It should be easy to apply.

(7) Regional Particular: in this research, Xining city is located at low latitude and high altitude plateau, where the climate is dry and cold; and human activities' impact to this land is very complicated; so when we choose the index system, we should think fully of the unique alpine eco-system in the area, and fully reflect the human activities impact on the ecological environment.

\subsection{Evaluation Index Selection and Index System Establishment}

Various eco-environmental factors in Xining area have the interactive relationship; they have bilateral influence and bilateral encouragement to each other. Reference to "eco-environmental quality evaluation technical requirements", the writer choose 23 evaluation factors accordingly, by using Five-laps-linkage Thought and Combining with the unique cold-arid landscape features of Loess Plateau-Qinghai-Tibet Plateau, finally establish a hierarchical structure of eco-environmental quality assessment index system in Xining area (Figure 1).

\subsection{The Meaning of Evaluation Index}

1) Fluctuation height of terrain (I1): Macro factor, which reflects the macro-topography, expressed by fluctuation height of terrain. Unit: $\mathrm{m}$;

2) Fracture development degree (I2): The extension length of fracture development in unit area. Unit: $\mathrm{km} / \mathrm{km}^{2}$;

3) Crustal stability (I3): Stability under dynamic action of internal earth in certain crustal surface region. Usually it is evaluated by geological caused earthquake's intensity level in this area. Unit: degree;

4) Geological disasters frequency (I4): In a certain period of time, the times that regional geological environment geology disasters affect in human production activities, generally counted by 1 year, 5 years or 10 . Unit: times/year;

5) Rock quality integrity (I5): indicate the influence of geological structure, the development situation, of rock structure, distribution, size, shape, groups number of cleavage, spacing, roughness of structure surface, alteration, filling or binding situation, using rock quality index RQD to express;

6) Soil types (II1): All of the sole types in certain areas, according to the soil change degree, it can be divided into: the bare land, building land, cultivated land and the soil in situ;

7) Constant nourishment lost degree (II2): The decrease ratio of soil nutrients content in adjacent time. Unit: \%;

8) River flow (III1): The amount of river gets through the certain transverse in unit time. Unit: $\mathrm{m}^{3} /$ hour;

9) Reservoir density (III2): The ratio of reservoir area per unit area. Unit: $\mathrm{km} / \mathrm{km}^{2}$;

10) Groundwater deficit index (IV1): The ratio of recharge and discharge of groundwater resources, it is the key index of groundwater balance;

11) Groundwater resources (IV2): The dynamic water that rainfall, surface water supplies of underground aquifer infiltration. Indicated by runoff modulus, unit: $\left(\mathrm{L} / \mathrm{s}^{*} \mathrm{~km}^{2}\right)$;

12) Accumulative temperature (VI2): Short for effective accumulative temperature, is the sum of the average temperature which are higher than critical temperature. For example, the daily average temperature $\geq 0{ }^{\circ} \mathrm{C}$ accumulative temperature and daily average temperature $\geq 10{ }^{\circ} \mathrm{C}$ accumulative temperature, etc. It is the sum of daily average temperature in crop growth and development stages. It is also a measurement of heat condition of crops' grow process and regional heat. Unit: degree*day;

13) Sunshine intensity (VI1): The altitude and latitude differences make the solar height angels and air condition differences, these factors lead the differences between receiving solar radiation and solar energy in regional area. Unit: $\mathrm{KJ} / \mathrm{km}^{2}$;

14) Annual precipitation (V1): The accumulation depth of liquid and solid (after the melting) precipitation from the sky without evaporation, seepage and loss in a year. Unit: $\mathrm{mm} / \mathrm{year}$;

15) Annual evaporation (V2): The amount of water evaporation to the air in a year. Unit: $\mathrm{mm} / \mathrm{year}$;

16) Vegetation types (VII1): In a certain area, all the vegetation can be divided into different classes according to families: artificial gardens, meadows, low shrub land, forest land; 
17) Vegetation coverage (VII2): The ratio of the vertical projection area divided by per unit area of each individual plant community overall, which reflects the vegetation thick degree and the size of the area of plant photosynthesis. It can be divided into projection coverage (all the strains coverage) and plant base coverage (base coverage), regardless of the determination of species, we use cover degree box method to determine this data. Unit: \%;

18) Animal types (VIII1): All animals in certain areas, according to the different kinds of food grade, they are divided into: decomposition, lower consumption level, intermediate consumption level, senior consumption level;

19) Grazing degrees (VIII2): The quantity of livestock, which does not affect the grass production capacity and ensure normal growth of the livestock in unit area of the grass in certain period. Pasture carrying index $=$ pasture's actual grazing capacity/pasture's theoretical grazing capacity;

20) Population density (IX1): The population per unit area. Unit: people/ $\mathrm{km}^{2}$;

21) Birth rate (IX2): The ratio of births (usually 1 year) divided by average population. It reflects the birth level of population, and we generally indicate it by thousandth. Birth rate= (births per year/average population per year) $\mathrm{X} 100 \%$. It is the important reason of natural population growth and a significant basis for us to research the demographic changes. Unit: \%;

22) Human development degree (X1): Human development degree is a measure of the strength of the regional human activities. Including land development, engineering construction, agriculture, forestry development, and animal husbandry development, etc;

23) Development degree (X2): Regional development level is the index that measure area social and economic development levels. The factors affected the difference of social and economic development levels including natural and humanistic etc.

\subsection{Assessment Index Data Selection}

After the selection of assessment index, we establish the assessment index system as follows in Table1.

\section{Building Mathematical Model of AHP}

After completed Eco-environmental quality assessment index selection, we will make a comprehensive assessment to each factor layer and every single element, by using expert evaluation method and AHP. In AHP, index value is a relative value by comparing the asperities between indexes, or called superiority weight. AHP provides us a scientific and simple way to determine the weights: two-factor comparison, confirm judgment matrix, and get superiority index weights (Table 2).

To determine the relative importance weight of influential factor, we should firstly establish the two-factor comparison judgment matrix, and then determine weights by using judgment matrix and inspection it accordingly. According to the initial judgment and sort, we determined that the importance of influential factors can be make a descending order as Man-made environment, groundwater environment, water climate environment, geological environment, population environment, surface water environment, climate environment, soil environment, biological environment and vegetation environment. Based on the ecological environment in Xining quality evaluation system, we design an expert scoring table. In this table, we set nine scales, from 1 to 9 , to indicate the influential factor importance. Through these comparisons, to establish a two-factor comparison judgment matrix.

There are three principles when we choose experts: First, he must be very familiar and accurate understanding with the history, today's situation and development trends of eco-environment in Xining; Second, he may have some idea of eco-environmental quality assessment, familiar with AHP principles and calculation; Third, he must be a academic leader or at least the chief ones in this field, and own a senior professional title.

After calculation, we can get:

$\mathrm{W} 2=(0.4651,0.1759,0.0928,0.0848,0.0664,0.0352,0.0232,0.0170,0.0066,0.0033) 2$

Ps: superscript 2 means the second layer of the hierarchical structure

Then, run consistency examination, calculate consistency ratio, judge the acceptability of the judgment matrix. The result is:

Consistency index $(\mathrm{CI}) \mathrm{CI}=0.0145$,

Random consistency ratio $(\mathrm{CR}) \mathrm{CR}=\mathrm{CI} / \mathrm{RI}=0.009416 \leq 0.01$. 
Thus, this judgment matrix is consistency matrix.

After the collation, we can get the weight and threshold value of major sensitive factor of eco-environmental quality in Xining area (Table 3).

\section{Assessment Result}

\subsection{Eco-environmental Quality Index Assessment}

Comprehensive index calculation of eco-environmental quality:

$$
E=\sum_{i=1}^{n} E_{i} W_{i}(\mathrm{n}=1,2, \cdots . .23)
$$

Ps: $E$ is eco-environmental quality comprehensive index; $W_{i}$ is the weight value of the factors; $E_{i}$ is the values of the I factors.

This paper makes an eco-environmental quality assessment to 10 sub-system's quality situation. Based on above formula, and the basic principle of evaluation, comprehensive every subsystems' quality, reflect eco-environment system's total quality. Therefore, the formula of hierarchical structure model and mathematical model of eco-environmental quality evaluation system is:

$$
\mathrm{DH}=\mathrm{A} a+\mathrm{B} b+\mathrm{C} c+\mathrm{D} d+\mathrm{E} e+\mathrm{F} f+\mathrm{G} g+\mathrm{H} h+\mathrm{I} i+\mathrm{J} j
$$

Ps: DH is the eco-environmental quality index; A, B, C, D, E, F, G, H, I, J respectively is the quality index of geological environment, soil environment, groundwater environment, surface water environment, water climate environment, climate environment, vegetation environment, biological environment, population environment, human activities environment; $\mathrm{a}, \mathrm{b}, \mathrm{c}, \mathrm{d}, \mathrm{e}, \mathrm{f}, \mathrm{g}, \mathrm{h}, \mathrm{i}, \mathrm{j}$ respectively is the weights of 10 subsystem.

According to the five-laps-linkage principle, we make a respectively analysis of lithosphere, hydrosphere, atmosphere, biosphere and social circle in Xining area:

1) Social circle is the dominant factor of eco-environment evolution in Xining city, the relative evaluation contributes is $53.16 \%$. The Qinghai-Tibet plateau is the most vulnerable ecological system and the most primitive area in our country, Xining is one of the highest levels of urbanization on the Qinghai-Tibet plateau, at high altitudes, cold climate, frequent natural calamity, low production potential is its characteristics. Figure 4 indicates the assessment result between each biological factor, by using traffic lights principle. From this figure, we could know that it is the urban where affect the 4 elements most. In addition, in the city and the counties, where have higher level of urbanization, are more influenced by human activities. Thus, how to control the impact to eco-environment from human being will be the focus of future researches, and it is also an entry point of human to intervene directly and effectively.

2) Water environment is the existence basis of Xining biosphere, and the contribution is the second, $21.11 \%$. It plays a decisive role in the eco-environment. Xining is located in cold-arid region, so the water resource has an important impact to plants and animals in this area. From the Figure 5, the higher level of urbanization of the area, the higher level of groundwater deficit; the density of rivers are uniformly distribution; reservoirs are mostly concentrated in Datong area; groundwater resources mainly distributed in valley region of Xining, but also owing to the higher urbanization level in valley area, lead to a higher groundwater deficit index.

3) Atmospheric environment is the most direct influential factor of Xining ecology environment, the contribution is $11.6 \%$. Evolution of climate environment affect the evolution of the ecological environment directly; global climate change is the most fundamental natural factors of Xining area and even the whole Qinghai-Tibet plateau environment deterioration, it makes fragile ecosystem even worse. The sunlight intensity, evaporation and precipitation are gradually reduced from west to the east, and the accumulative temperature is lower in south and north, higher in the middle. Climate can not be changed in short time, but we can make it change slower or stop climatic change by reducing greenhouse gas emissions.

4) The contribution of rock environment is $10.18 \%$. Soil of Xining area belongs to mountainous plateau. Along with the elevation from high to low, the soil type can be divided into bedrock bare land, soil in situ, cultivated land and building land.

5) The contribution of biology environment is $3.96 \%$. Animal husbandry is not the dominant industry in Xining, productivity level generally keep in a primitive production status, grazing degree is lower. In recent years, the industrial development took the target of protecting eco-environment, deducted many resources development-oriented industries, while increased many biological industries like bio-medicine. The more 
vegetation coverage and vegetation types are, the lower grazing degree and animal type are.

According to the national trial Eco-environmental Quality division standard, and combined with the natural geographical conditions and the ecological environment performance in Xining, the Eco-environmental quality in Xining is divided into 4 level, after added the above results of five spheres, then we corresponded them to ecological geological environment quality index (Table 4, Figure 7).

From Eco- environment evaluation map, we could see that the area of the poor quality $(4 \leq \mathrm{DH}<5)$ and the better quality $(\mathrm{DH}<3)$ are the largest, this suggests that the eco-environment of Xining is in a less stable state which can change easily while the factors change. We should strengthen protection of the Eco-environment; make the change of various factors is favorable for development and eco-environment protection. In addition, from Figure 3, Eco-environmental quality become well from the centre to peripheral in Xining, that's to say, when the urbanization is higher, the eco-environmental quality becomes worse.

\section{Conclusion}

According to the above analysis, we can draw a conclusion that, from the influence factors, contribution rate of social circle, hydrosphere, atmosphere, lithosphere and biosphere, which are from Five-laps-linkage principle, reduced in turn, were $53.16 \%, 21.11 \%, 11.6 \%, 10.18 \%$ and $3.96 \%$. Social circle is the dominant factors eco-environment evolution in Xining area. It suggested that urbanization influenced the Eco-environmental quality severely; human beings keep changing the regional eco-environment by city construction and industry development. Water, atmosphere, soil also influenced the quality in some degree, so we should strengthen the natural ecology protection, especially the ecologically fragile areas. The influence from biosphere is the lowest, mainly because this region is the most urbanized region, with less pasture and underdeveloped animal husbandry.

Therefore, to achieve the target of healthy development of Eco-environment in Xining, we should prevent aggressive types of urbanization process, change the idea from perusing urbanization quantity to quality, develop the ecological industries, improve the poor Eco-environmental quality in some area, use the principle of coordinated development between resource, environment and economy, and lead the regional urbanization.

Due to dependency on expert to scoring the AHP and determine the weights of each part, there may still exist some subjectivity, this depends on the understanding of experts and the depth of understanding in different fields. Thus, in the future further study, we should use more detailed data and more objective methods to make eco-environmental quality evaluation, and compare with this paper, increase the credibility of the researching results.

\section{References}

Ecological function zoning temporary technical point of order, State. (2002). Administration of Environment.

Hai, R. T., \& Wang, W. X. (2004). Evaluation of the ecological environment, planning and management. China Environmental Science Press.

Hu, A. Y., Guo, S. L., et al. (2006). Ecologic Environment Quality fuzzy comprehensive evaluation in the Inland river basin. Jounal of Geologica Hazards and Environment Preservation.

Huang, B. J., Wang, S. P., \& Yang, H. Z. (2009). City Eco. environment Quality Assessment Based on GIS and RS. Journal of Tongji University (Natural Science), 805-809.

Jin, L., Wang, Z. T., Zhu, X. L., et al. (1992). Environment and Ecology. Beijing: HIGHER EDUCATION PRESS.

Li, S., Qiu, W., et al. (2006). Applying Analytical Hierarchy Process to Assess Eco-Environment Quality of Heilongjiang Province. Environmental Science.

Li, B., Song, Y. N., Yang, B. B., et al. (2009). Study on Eco-Environmental Quality Evaluation of Shenyang City. Journal of Shenyang Normal University (Natural Science), 373-377.

Li, H. Y., Luo, C. Y., Gao, Y. H., et al. (2009). Research on regional eco-environment quality assessment index system-take Heilongjiang Province as an exampl. Territory \& Natural Resources Study, 67-68.

Wu, J. G. (2000). Landscape Ecology. Beijing: HIGHER EDUCATION PRESS.

Yang, S., Chu, Y., et al. (2002). Application of Analytic Hierachy Process (AHP) in the evaluation of the Geo-environmental quality in the Sangjiang plain. Geological Bulletin of China.

Zhou, H. K., Zhao, X. Q., Zhou, L., et al. (2005). Application of Analytic Hierachy Process on the Alpine Grassland Degradation in the Source Region of the Yangtze and Yellow Rivers. Scientific resources.

Zhu, X. H., Yang, X. C., et al. (2001). Application of AHP Method in Regional Eco-environmental Quality Evaluation. Land and Resources Management Technology. 
Table 1. List of Eco-environmental quality (Vulnerability) assessmentindex system of Xining City

\begin{tabular}{|c|c|c|c|c|c|}
\hline Influential factor layers & Influential factors and its code & & Qualitative or q & ntitative index & \\
\hline \multirow{14}{*}{$\underset{\text { (I) }}{\text { Geological environment }}$} & \multirow{3}{*}{ Fluctuation height of terrain (unit: m)(I1) } & Flat & Hilly & Underfeature & $\begin{array}{l}\text { Medium } \\
\text { Fluctuation }\end{array}$ \\
\hline & & $<30$ & $30-200$ & $200-500$ & $>500$ \\
\hline & & 1 & 2 & 3 & 4 \\
\hline & \multirow{3}{*}{$\begin{array}{l}\text { Fracture development degree (unit: } \\
\left.\qquad \mathrm{km} / \mathrm{km}^{2}\right)(\mathrm{I} 2)\end{array}$} & Null & Weak & Medium & Strong \\
\hline & & $<0.2$ & $0.2-0.3$ & $0.3-0.4$ & $>0.4$ \\
\hline & & 1 & 2 & 3 & 4 \\
\hline & \multirow{3}{*}{ Crustal stability (unit: degree)(I3) } & Stable & Mild stable & Medium stable & Unstable \\
\hline & & 0 & $<5$ & $5-7$ & $>7$ \\
\hline & & 1 & 2 & 3 & 4 \\
\hline & \multirow{2}{*}{$\begin{array}{l}\text { Geological disasters frequency (unit: } \\
\text { times/year)(I4) }\end{array}$} & Infrequent & Mild frequent & $\begin{array}{l}\text { Medium } \\
\text { frequent }\end{array}$ & $\begin{array}{l}\text { Severe } \\
\text { frequent }\end{array}$ \\
\hline & & 1 & 2 & 3 & 4 \\
\hline & \multirow{3}{*}{ Rock quality integrity(I5) } & $>0.75$ & $0.75-0.55$ & $0.55-0.25$ & $0.25>$ \\
\hline & & Complete & $\begin{array}{l}\text { Comparatively } \\
\text { complete }\end{array}$ & Less complete & Incomplete \\
\hline & & 1 & 2 & 3 & 4 \\
\hline \multirow{4}{*}{ Soil environment(II) } & \multirow{2}{*}{ Soil types(II1) } & Bare land & Building land & $\begin{array}{l}\text { Cultivated } \\
\text { land }\end{array}$ & Soil in situ \\
\hline & & 1 & 2 & 3 & 4 \\
\hline & \multirow{2}{*}{$\begin{array}{c}\text { Constant nourishment lost degree } \\
\text { (unit: \%)(II2) }\end{array}$} & No loss & Mild loss & Medium loss & Severe loss \\
\hline & & 1 & 2 & 3 & 4 \\
\hline \multirow{5}{*}{$\begin{array}{l}\text { Surface water } \\
\text { environment } \\
\text { (III) }\end{array}$} & \multirow{3}{*}{ River flow (unit: $\mathrm{m}^{3} /$ hour)(III1) } & Weak & Medium & Less strong & strong \\
\hline & & $<1>$ & $1-100$ & $100-200$ & 200 \\
\hline & & 1 & 2 & 3 & 4 \\
\hline & \multirow{2}{*}{ Reservoir density (unit: $\mathrm{km} / \mathrm{km}^{2}$ )(III2) } & Null & Mild & Medium & Severe \\
\hline & & 1 & 2 & 3 & 4 \\
\hline \multirow{5}{*}{$\begin{array}{c}\text { Groundwater } \\
\text { Environment(IV) }\end{array}$} & \multirow{2}{*}{ Groundwater deficit index(IV1) } & Not deficit & Mild deficit & Mild deficit & $\begin{array}{l}\text { Severe } \\
\text { deficit }\end{array}$ \\
\hline & & 1 & 2 & 3 & 4 \\
\hline & & Poor & Medium & Rich & Very rich \\
\hline & $\begin{array}{l}\text { Groundwater resources (unit: } \\
\left.\left(\mathrm{L} / \mathrm{s}^{*} \mathrm{~km}^{2}\right)\right)(\mathrm{IV} 2)\end{array}$ & $<1$ & $1-3$ & $3-6$ & $>6$ \\
\hline & & 1 & 2 & 3 & 4 \\
\hline \multirow{6}{*}{$\begin{array}{l}\text { Water climate } \\
\text { environment } \\
\text { (V) }\end{array}$} & \multirow{3}{*}{ Precipitation (unit: $\mathrm{mm})(\mathrm{V} 1)$} & weak & Medium & Less strong & strong \\
\hline & & $<200$ & $200-400$ & $400-600$ & $>600$ \\
\hline & & 1 & 2 & 3 & 4 \\
\hline & & weak & Medium & Less strong & strong \\
\hline & Evaporation (unit: $\mathrm{mm})(\mathrm{V} 2)$ & $<300$ & $300-400$ & $400-500$ & $>500$ \\
\hline & & 1 & 2 & 3 & 4 \\
\hline \multirow{5}{*}{$\begin{array}{c}\text { Climate } \\
\text { environment(VI) }\end{array}$} & Sunshine intensity (unit. KJ/km² ${ }^{2}$ (VI) & weak & Medium & Less strong & strong \\
\hline & 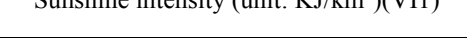 & 1 & 2 & 3 & 4 \\
\hline & & low & Medium & Less high & high \\
\hline & $\begin{array}{c}\text { Accumulative temperature (unit: } \\
\text { degree*day)(VI2) }\end{array}$ & $<200$ & $200-750$ & $750-2000$ & $>2000$ \\
\hline & & 1 & 2 & 3 & 4 \\
\hline & & low & Less low & medium & high \\
\hline & Vegetation coverage (unit: \%)(VII1) & $<10 \%$ & $10 \%-30 \%$ & $30 \%-70 \%$ & $>70 \%$ \\
\hline Vegetation environment & & 1 & 2 & 3 & 4 \\
\hline & Vegetation types(VII2) & $\begin{array}{l}\text { Artificial } \\
\text { gardens }\end{array}$ & meadows & low shrub land & forest land \\
\hline & 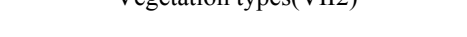 & 1 & 2 & 3 & 4 \\
\hline & Animal types(VIII1) & $\begin{array}{c}\text { decomposit1 } \\
\text { on }\end{array}$ & $\begin{array}{c}\text { lower } \\
\text { consumption }\end{array}$ & $\begin{array}{l}\text { intermediate } \\
\text { consumption }\end{array}$ & $\begin{array}{c}\text { senior } \\
\text { consumption }\end{array}$ \\
\hline Biological environment & & 1 & 2 & 3 & 4 \\
\hline (VIII) & Grazing degrees(VIII2) & $\begin{array}{c}\text { Not } \\
\text { overload }\end{array}$ & Mild overload & $\begin{array}{l}\text { Medium } \\
\text { overload }\end{array}$ & $\begin{array}{c}\text { Severe } \\
\text { overload }\end{array}$ \\
\hline & & 1 & 2 & 3 & 4 \\
\hline & & Null & mild & medium & severe \\
\hline & Population density (unit: person $/ \mathrm{km}^{2}$ )(IX1) & 0 & $<50$ & $50-399$ & $>400$ \\
\hline $\begin{array}{l}\text { Population environment } \\
\text { (IX) }\end{array}$ & & 1 & 2 & 3 & 4 \\
\hline & Birth rate (Unit. \%)(IX2) & Null & mild & medium & severe \\
\hline & & 1 & 2 & 3 & 4 \\
\hline & Human development degree(X1) & Null & mild & medium & severe \\
\hline Man-made environment & & 1 & 2 & 3 & 4 \\
\hline$(\mathrm{X})$ & Development degree(X2) & original & Mild developed & $\begin{array}{c}\text { Medium } \\
\text { developed }\end{array}$ & $\begin{array}{c}\text { Severe } \\
\text { developed }\end{array}$ \\
\hline & 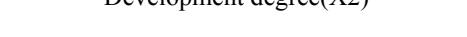 & 1 & 2 & 3 & 4 \\
\hline
\end{tabular}


Table 2. Weight data sheet of Criterion layer and Sub-criterion layer, weight date sheet of program layer

\begin{tabular}{|c|c|c|c|c|c|c|c|}
\hline Index & Criterion index & $\begin{array}{c}\text { Matrix } \\
\text { consistency }\end{array}$ & Weight to & \multicolumn{4}{|c|}{ program layer weight data sheet } \\
\hline \multicolumn{4}{|c|}{ Criterion layer } & Program index & weight & Program index & weight \\
\hline 1 & Lithosphere & 0 & 0.1018 & Vegetation coverage & 0.0247 & Soil types & 0.0127 \\
\hline 2 & Hydrosphere & 0 & 0.2111 & $\begin{array}{l}\text { Reduction degree of } \\
\text { pasture productivity }\end{array}$ & 0.0082 & $\begin{array}{c}\text { Constant } \\
\text { nourishment lost } \\
\text { degree }\end{array}$ & 0.0042 \\
\hline 3 & Atmosphere & 0 & 0.1160 & Animal types & 0.0009 & $\begin{array}{l}\text { Accumulative } \\
\text { temperature }\end{array}$ & 0.0046 \\
\hline 4 & Biosphere & 0 & 0.0396 & Grazing degrees & 0.0057 & Sunshine intensity & 0.0186 \\
\hline 5 & Social circle & 0 & 0.5316 & River flow & 0.1466 & precipitation & 0.0773 \\
\hline \multicolumn{4}{|c|}{ Sub-criterion layer } & Reservoir density & 0.0293 & evaporation & 0.0155 \\
\hline I & $\begin{array}{c}\text { Geological } \\
\text { environment }\end{array}$ & 0.0379 & 0.0848 & Groundwater resources & 0.0059 & & \\
\hline II & Soil environment & 0 & 0.0170 & Groundwater deficit index & 0.0293 & & \\
\hline III & $\begin{array}{c}\text { Surface water } \\
\text { environment }\end{array}$ & 0 & 0.1759 & Population density & 0.0166 & & \\
\hline IV & $\begin{array}{l}\text { Groundwater } \\
\text { environment }\end{array}$ & 0 & 0.0352 & Birth rate & 0.0498 & & \\
\hline $\mathrm{V}$ & $\begin{array}{l}\text { Water climate } \\
\text { environment }\end{array}$ & 0 & 0.0928 & $\begin{array}{c}\text { Human development } \\
\text { degree }\end{array}$ & 0.4070 & & \\
\hline VI & $\begin{array}{c}\text { Climate } \\
\text { environment }\end{array}$ & 0 & 0.0232 & development degree & 0.0581 & & \\
\hline VII & $\begin{array}{c}\text { Vegetation } \\
\text { environment }\end{array}$ & 0 & 0.0033 & Terrain fluctuation degree & 0.0395 & & \\
\hline VIII & $\begin{array}{c}\text { Biological } \\
\text { environment }\end{array}$ & 0 & 0.0066 & $\begin{array}{c}\text { Fracture development } \\
\text { degree }\end{array}$ & 0.0129 & & \\
\hline IX & $\begin{array}{c}\text { Population } \\
\text { environment }\end{array}$ & 0 & 0.0664 & Crustal stability & 0.0161 & & \\
\hline $\mathrm{X}$ & $\begin{array}{c}\text { an-made } \\
\text { environment }\end{array}$ & 0 & 0.4651 & $\begin{array}{l}\text { geological disasters } \\
\text { frequency } \\
\end{array}$ & 0.0071 & & \\
\hline \multicolumn{2}{|c|}{$\begin{array}{l}\text { Eco-environment system in } \\
\text { Xining city }\end{array}$} & 0.0145 & 1.0000 & integrity of rock quality & 0.0092 & & \\
\hline
\end{tabular}


Table 3. Weight and threshold value of major sensitive factor of eco-environmental quality in Xining area

\begin{tabular}{|c|c|c|c|c|c|c|}
\hline \multirow[b]{2}{*}{$\begin{array}{l}\text { Influential factor } \\
\text { layer }\end{array}$} & \multirow[b]{2}{*}{$\begin{array}{l}\text { Sensitive factor layer } \\
\text { code }\end{array}$} & \multirow{2}{*}{$\begin{array}{c}\text { Relatively } \\
\text { importance } \\
\text { weight of } \\
\text { influential } \\
\text { factor layer }\end{array}$} & \multirow[b]{2}{*}{$\begin{array}{c}\text { Relatively } \\
\text { weight of } \\
\text { sensitive factor } \\
\text { layer }\end{array}$} & \multirow[b]{2}{*}{$\begin{array}{l}\text { Superiority weight } \\
\text { of factor } \\
\text { combination }(\mathrm{Ci})\end{array}$} & \multicolumn{2}{|c|}{ Threshold value } \\
\hline & & & & & $\begin{array}{l}\text { Minimum } \\
\text { value }\end{array}$ & $\begin{array}{l}\text { Maximum } \\
\text { value }\end{array}$ \\
\hline \multirow{5}{*}{$\begin{array}{c}\text { Geological } \\
\text { environment (I) }\end{array}$} & $\begin{array}{c}\text { Fluctuation height of } \\
\text { terrain(I1) }\end{array}$ & \multirow{5}{*}{0.0848} & 0.0395 & 0.0033496 & 1 & 4 \\
\hline & $\begin{array}{c}\text { Fracture development } \\
\text { degree(I2) }\end{array}$ & & 0.0129 & 0.00109392 & 2 & 3 \\
\hline & Crustal stability(I3) & & 0.0161 & 0.00136528 & 2.2 & 8.1 \\
\hline & $\begin{array}{c}\text { Geological disasters } \\
\text { frequency(I4) }\end{array}$ & & 0.0071 & 0.00060208 & 1 & 4 \\
\hline & $\begin{array}{l}\text { Rock quality } \\
\text { integrity(I5) }\end{array}$ & & 0.0092 & 0.00078016 & 0.13 & 0.9 \\
\hline \multirow{2}{*}{$\begin{array}{l}\text { Soil environment } \\
\text { (II) }\end{array}$} & Soil types(II1) & \multirow[b]{2}{*}{0.0170} & 0.0127 & 0.0002159 & 1 & 4 \\
\hline & $\begin{array}{c}\text { Constant nourishment } \\
\text { lost degree(II2) }\end{array}$ & & 0.0042 & 0.0000714 & 1 & 4 \\
\hline \multirow[b]{2}{*}{$\begin{array}{c}\text { Surface water } \\
\text { environment (III) }\end{array}$} & River flow(III1) & \multirow[b]{2}{*}{0.1759} & 0.1466 & 0.02578694 & 12 & 200 \\
\hline & $\begin{array}{l}\text { Reservoir density } \\
\text { (III2) }\end{array}$ & & 0.0293 & 0.00515387 & 1 & 4 \\
\hline \multirow{2}{*}{$\begin{array}{c}\text { Groundwater } \\
\text { Environment (IV) }\end{array}$} & $\begin{array}{c}\text { Groundwater deficit } \\
\text { index(IV1) }\end{array}$ & \multirow{2}{*}{0.0352} & 0.0059 & 0.00020768 & 1 & 4 \\
\hline & $\begin{array}{c}\text { Groundwater } \\
\text { resources(IV2) }\end{array}$ & & 0.0293 & 0.00103136 & 1 & 4 \\
\hline \multirow{2}{*}{$\begin{array}{l}\text { Water climate } \\
\text { environment }(\mathrm{V})\end{array}$} & $\begin{array}{c}\text { Annual } \\
\text { precipitation(V1) }\end{array}$ & \multirow{2}{*}{0.0928} & 0.0073 & 0.00067744 & 200 & 600 \\
\hline & $\begin{array}{c}\text { Annual } \\
\text { evaporation(V2) }\end{array}$ & & 0.0155 & 0.0014384 & 800.8 & 13250.8 \\
\hline \multirow{2}{*}{$\begin{array}{c}\text { Climate } \\
\text { environment (VI) }\end{array}$} & $\begin{array}{l}\text { Sunshine intensity } \\
\text { (VI1) }\end{array}$ & \multirow{2}{*}{0.0232} & 0.0186 & 0.00043152 & 2034.2 & 3074.4 \\
\hline & $\begin{array}{c}\text { Accumulative } \\
\text { temperature(VI2) }\end{array}$ & & 0.0046 & 0.00010672 & 0.15 & 55 \\
\hline \multirow{2}{*}{$\begin{array}{l}\text { Vegetation } \\
\text { environment } \\
\text { (VII) }\end{array}$} & $\begin{array}{c}\text { Vegetation } \\
\text { coverage(VII1) }\end{array}$ & \multirow{2}{*}{0.0033} & 0.0247 & 0.00008151 & 1 & 4 \\
\hline & $\begin{array}{c}\text { Vegetation types } \\
\text { (VII2) }\end{array}$ & & 0.0082 & 0.00002706 & 1 & 4 \\
\hline \multirow{2}{*}{$\begin{array}{c}\text { Biological } \\
\text { environment } \\
\text { (VIII) } \\
\end{array}$} & Animal types(VIII1) & \multirow[b]{2}{*}{0.0066} & 0.0009 & 0.00000594 & 1 & 4 \\
\hline & $\begin{array}{c}\text { Grazing degrees } \\
\text { (VIII2) }\end{array}$ & & 0.0057 & 0.00003762 & 1 & 4 \\
\hline \multirow{2}{*}{$\begin{array}{c}\text { Population } \\
\text { environment (IX) }\end{array}$} & $\begin{array}{l}\text { Population density } \\
\text { (IX1) }\end{array}$ & \multirow[t]{2}{*}{0.0664} & 0.0166 & 0.00110224 & 1 & 4 \\
\hline & Birth rate(IX2) & & 0.0498 & 0.00330672 & 1 & 4 \\
\hline \multirow{2}{*}{$\begin{array}{c}\text { Human } \\
\text { environment }(\mathrm{X})\end{array}$} & $\begin{array}{c}\text { Human development } \\
\text { degree(X1) }\end{array}$ & \multirow{2}{*}{0.4651} & 0.4070 & 0.1892957 & 1 & 4 \\
\hline & $\begin{array}{c}\text { Development } \\
\text { degree }(\mathrm{X} 2)\end{array}$ & & 0.0581 & 0.02702231 & 1 & 4 \\
\hline
\end{tabular}

Table 4. Grading standard of eco-environmental quality in Xining area

\begin{tabular}{c|c|c|c|c}
\hline $\begin{array}{c}\text { Degree of advantages and disadvantages in } \\
\text { eco-environmental quality }\end{array}$ & (I) bad & (II) less bad & (III) Medium \\
\hline Eco-environmental quality index & $\mathrm{DH}>5$ & $4 \leq \mathrm{DH}<5$ & $3 \leq \mathrm{DH}<4$ & $\mathrm{DH}<3$ \\
\hline
\end{tabular}




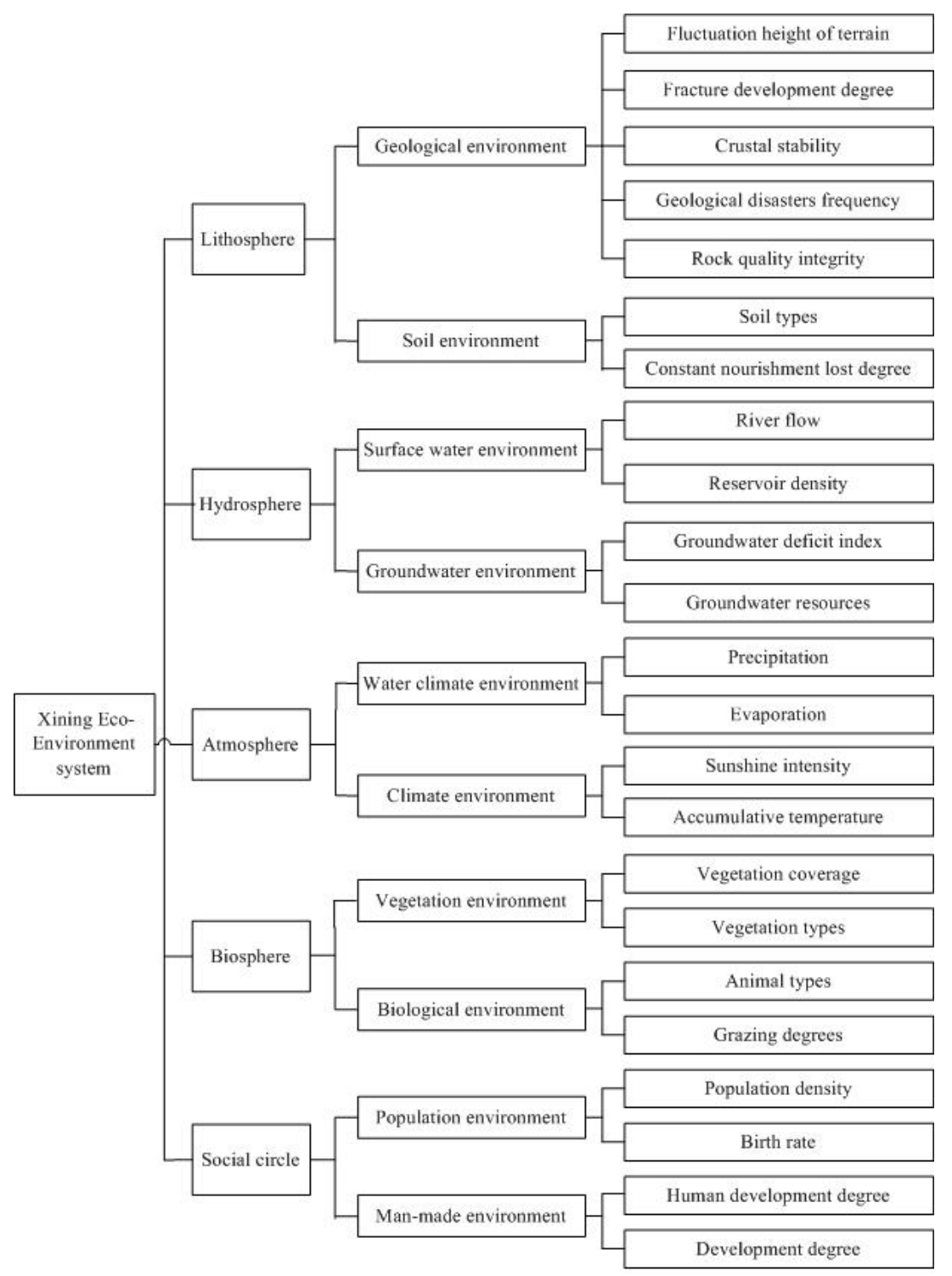

Figure 1. Model hierarchic structural representation of Xining Eco-Environment system 


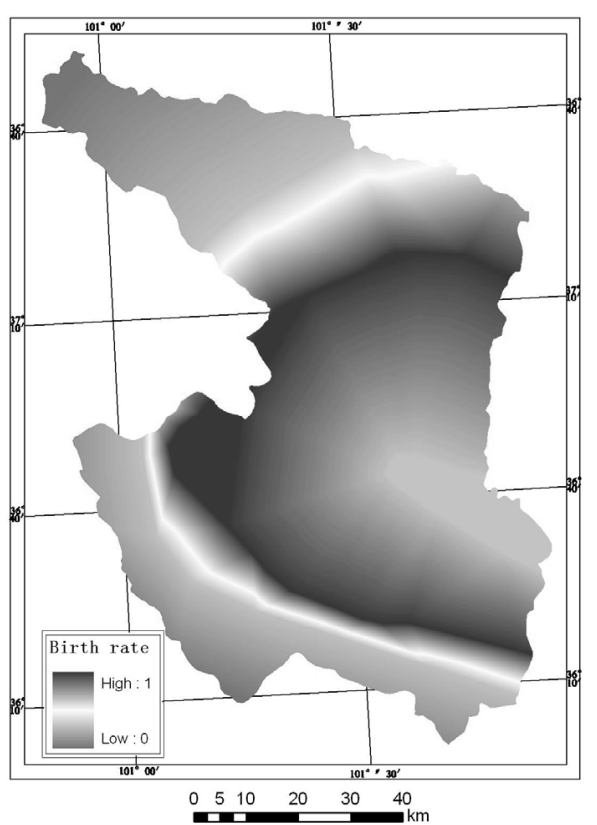

a)

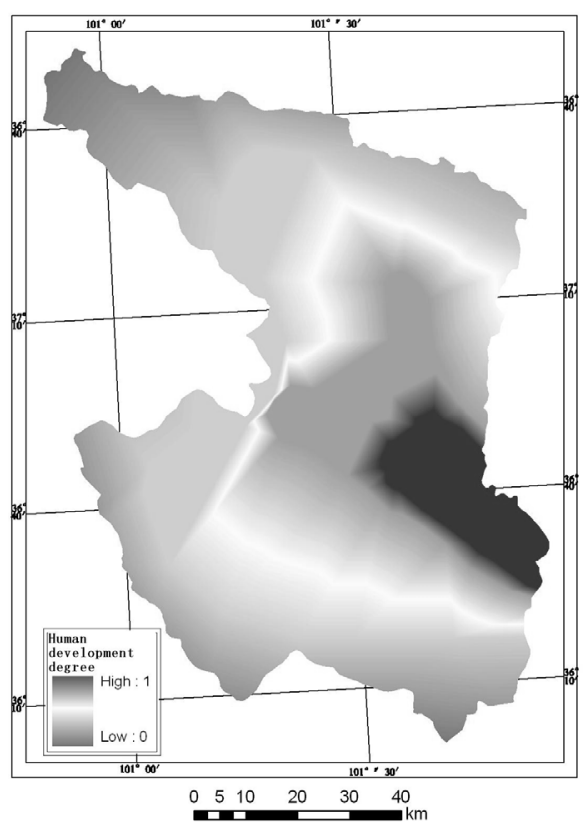

c)

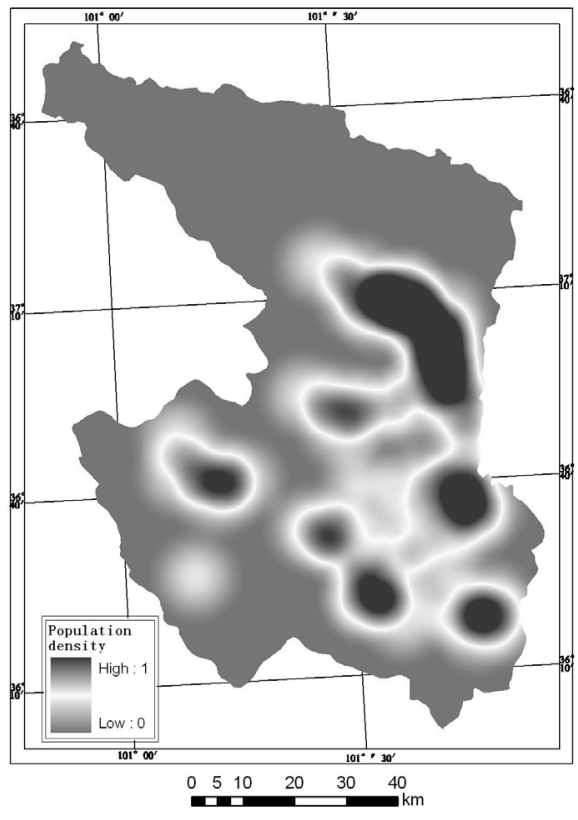

b)

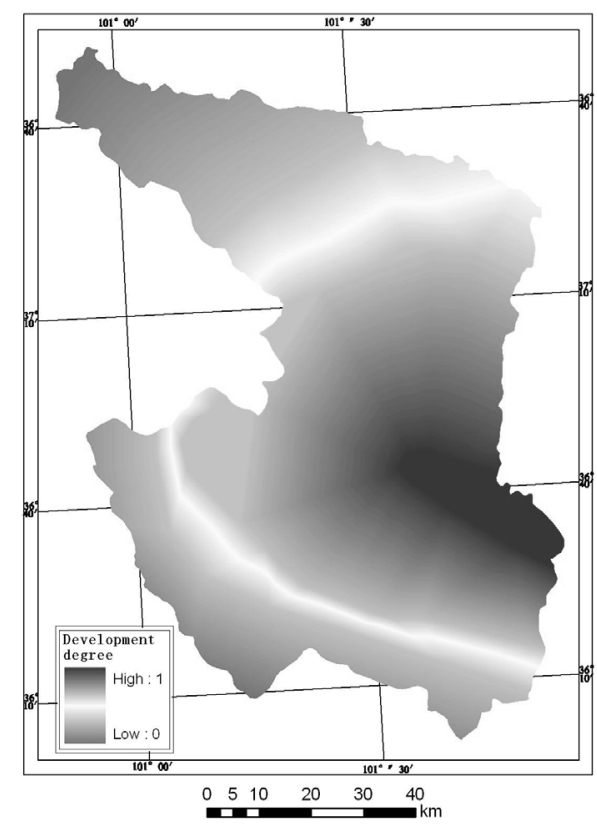

d)

Figure 2. Assessment results of biosphere factors 


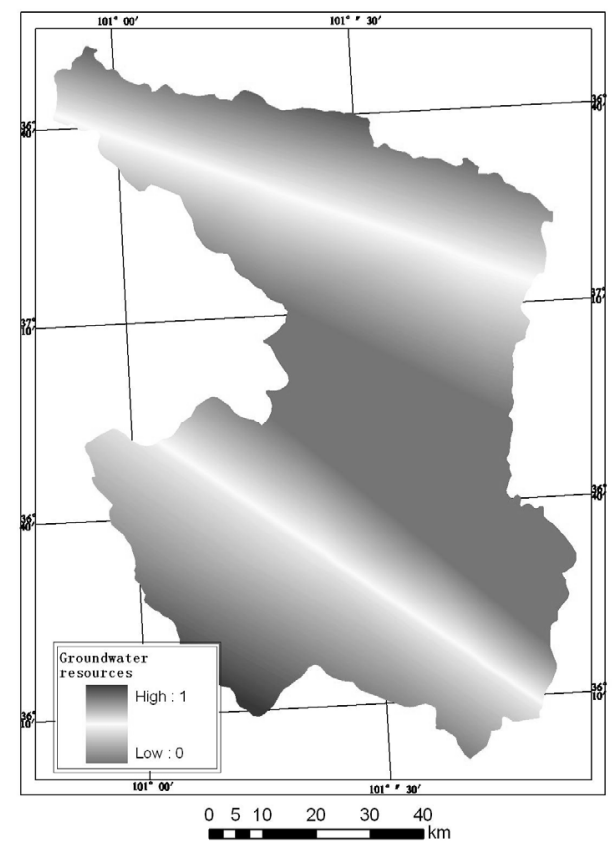

a)

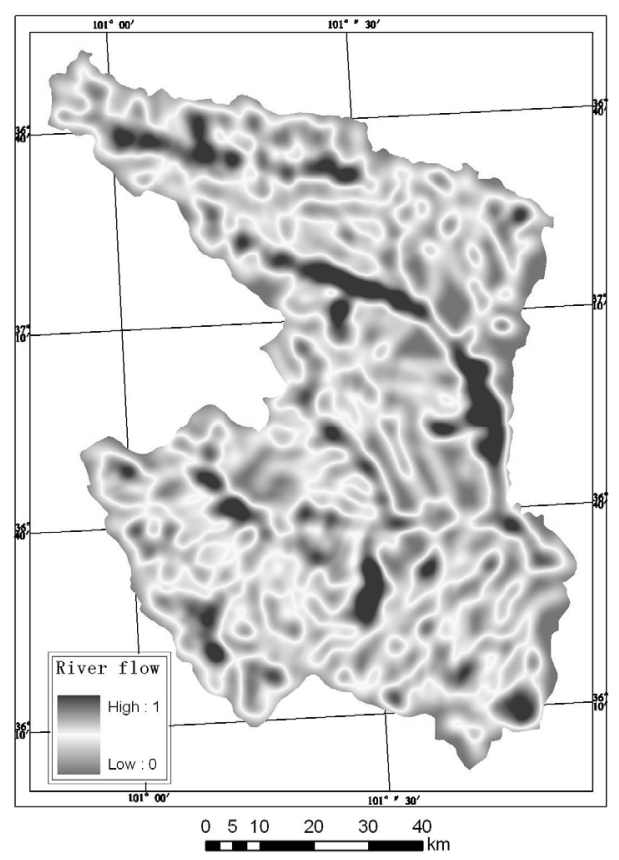

c)

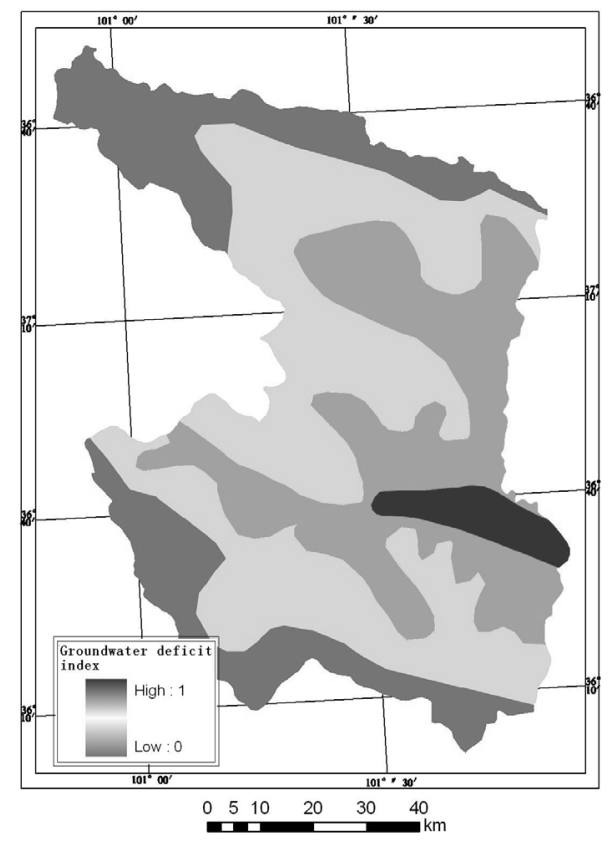

b)

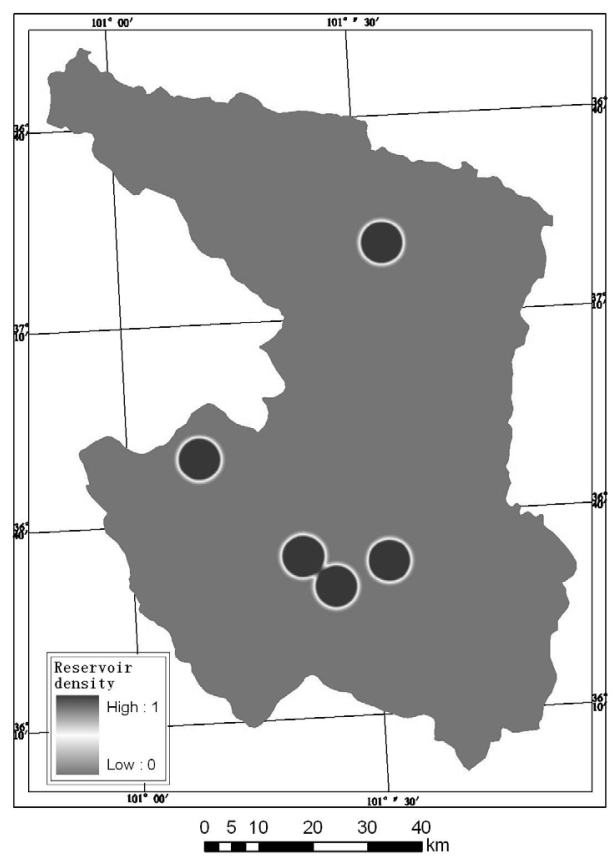

d)

Figure 3. Assesssment results of hydrosphere factors 


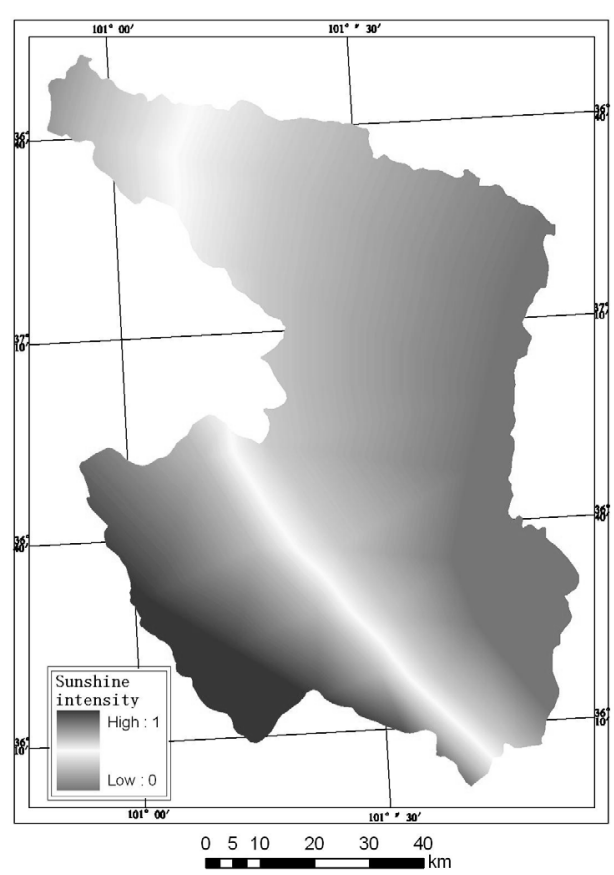

a)

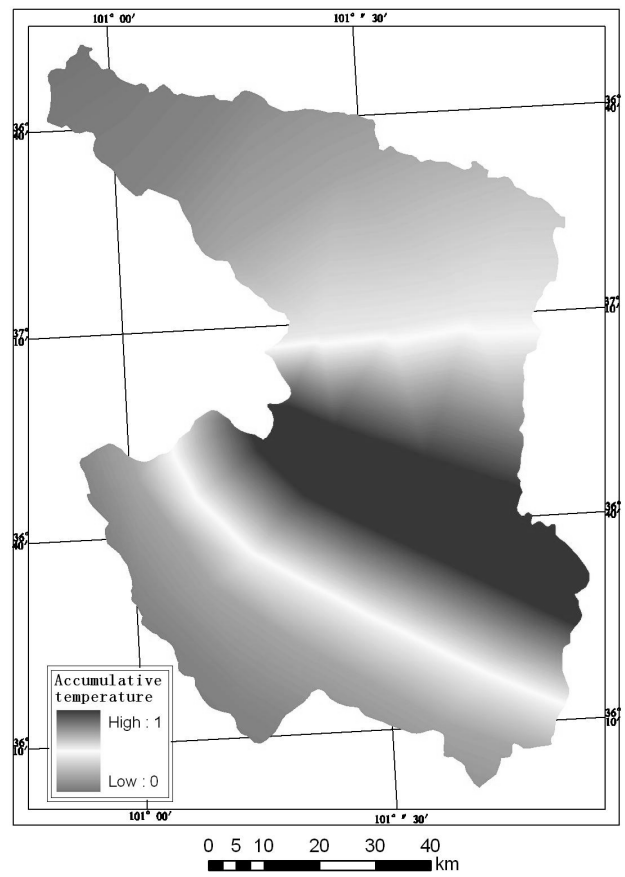

c)

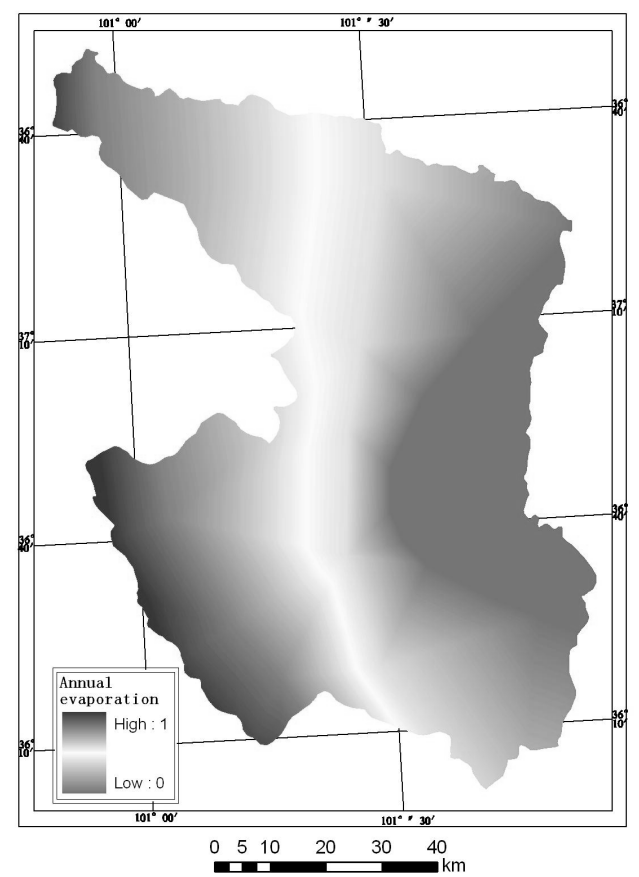

b)

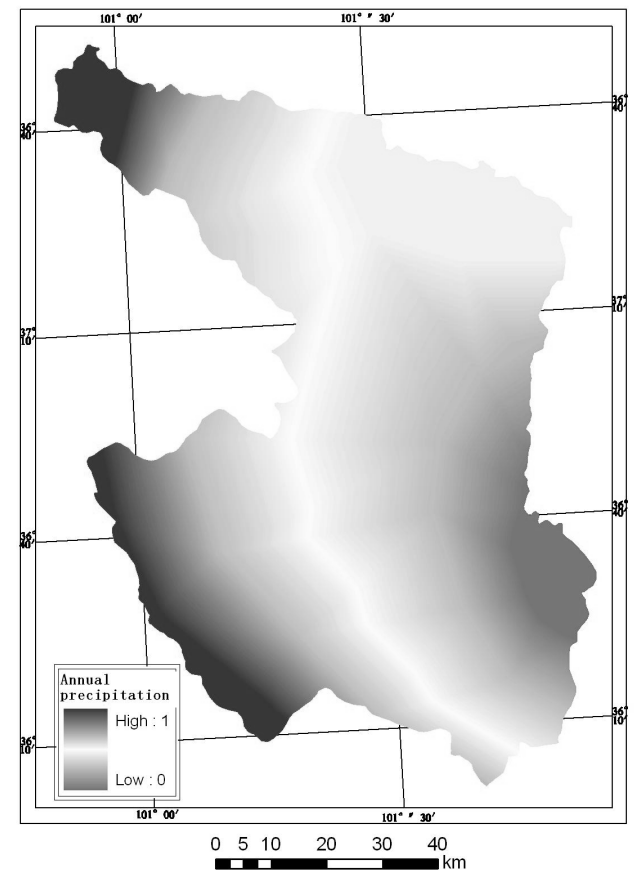

d)

Figure 4. Assessment results of atmosphere factors 


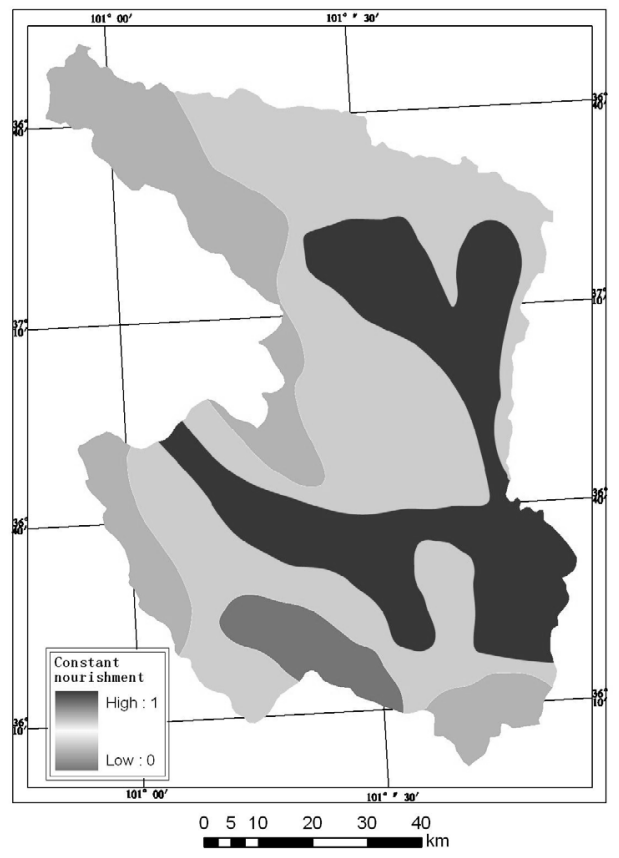

a)

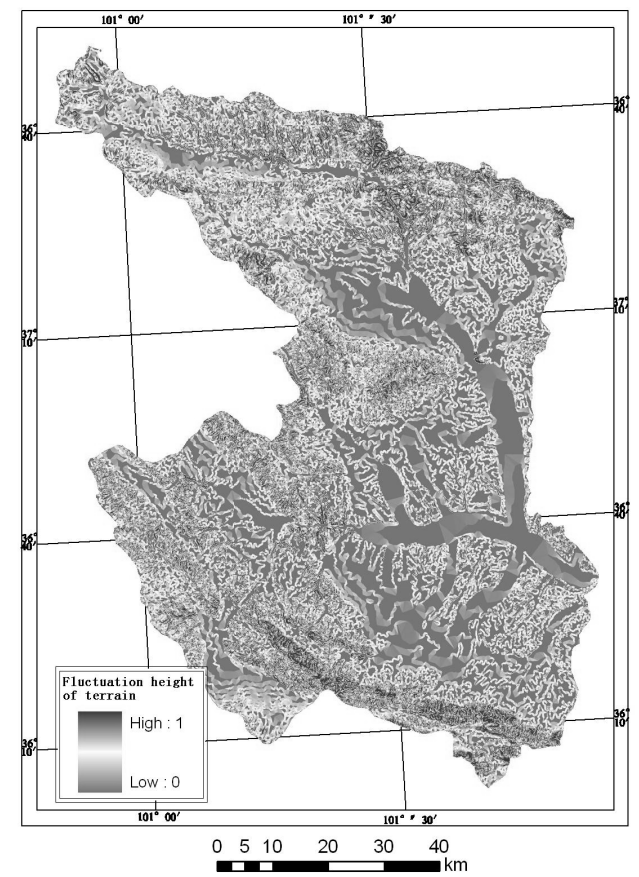

c)

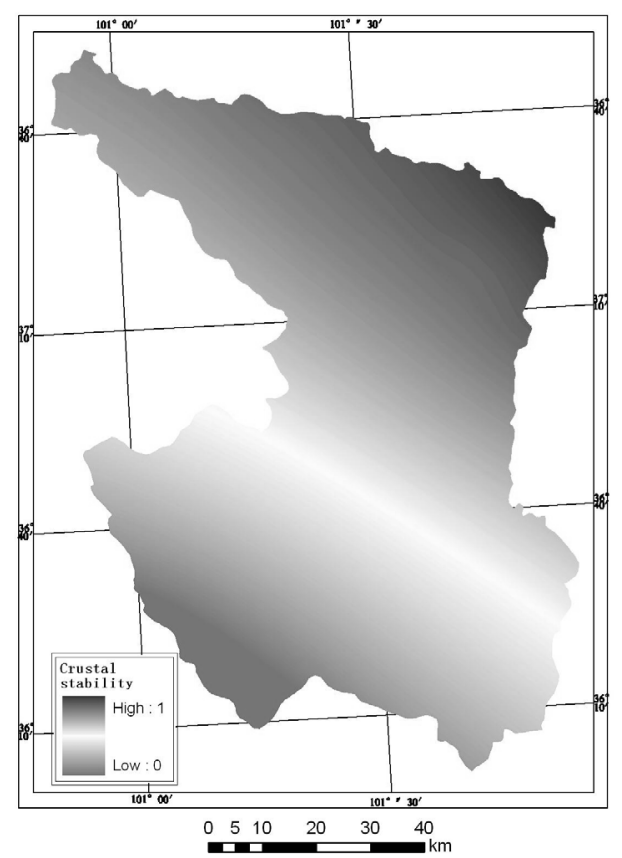

b)

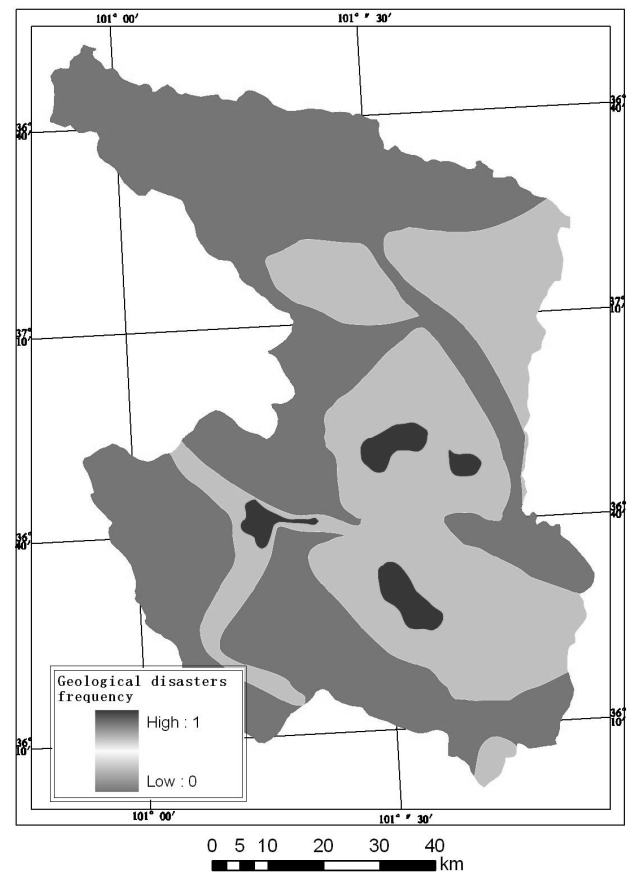

d)

Figure 5-1. Assessment results of lithosphere factors 


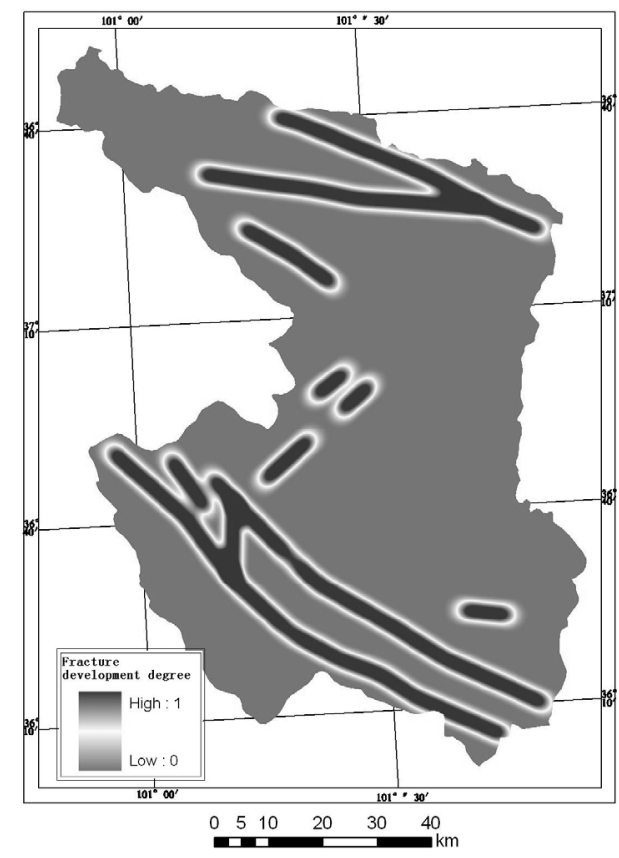

e)

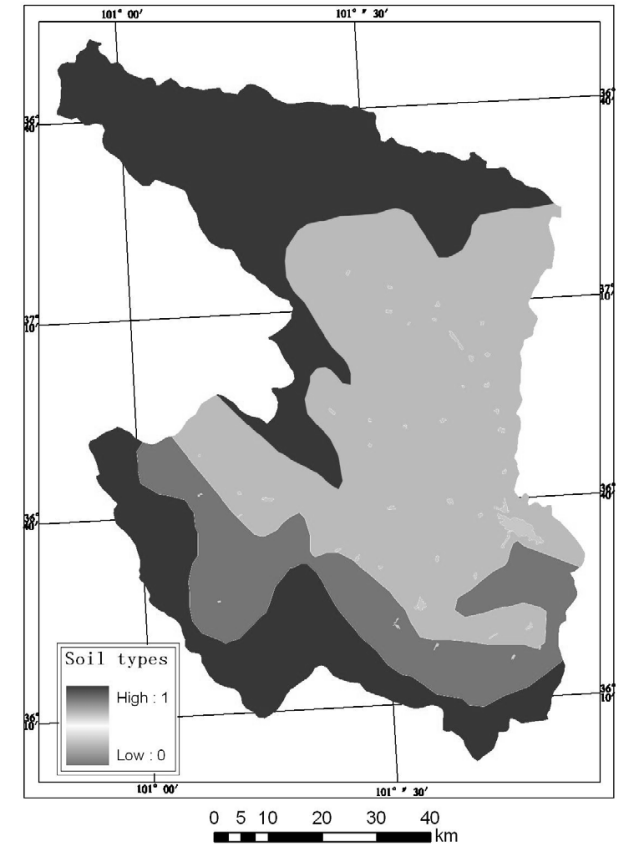

f)

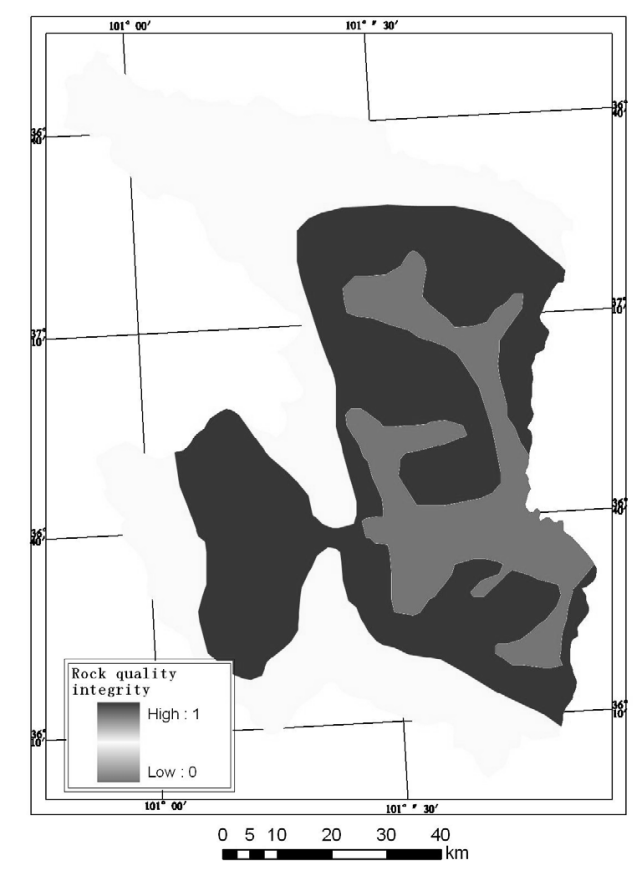

g)

Figure 5-2. Assessment results of lithosphere factors 


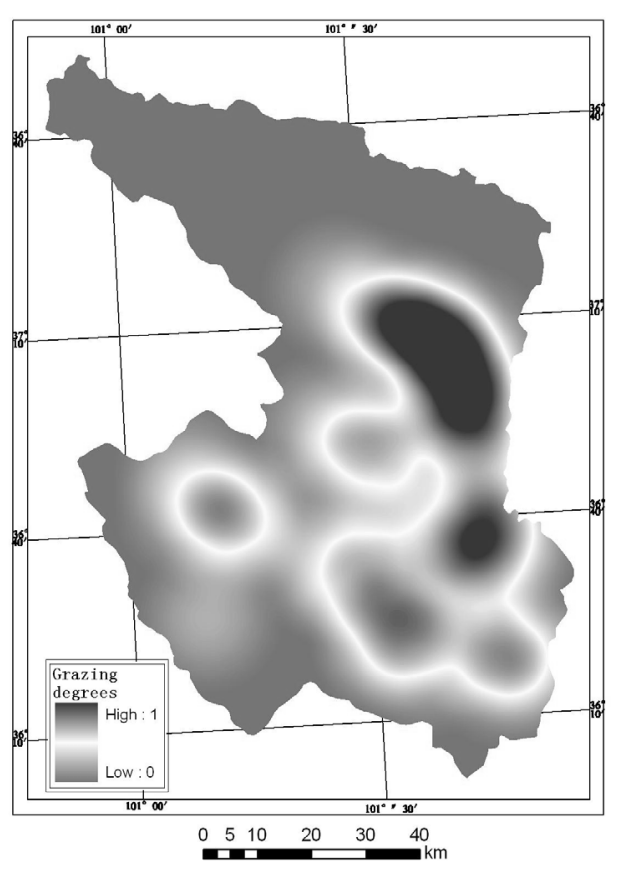

a)

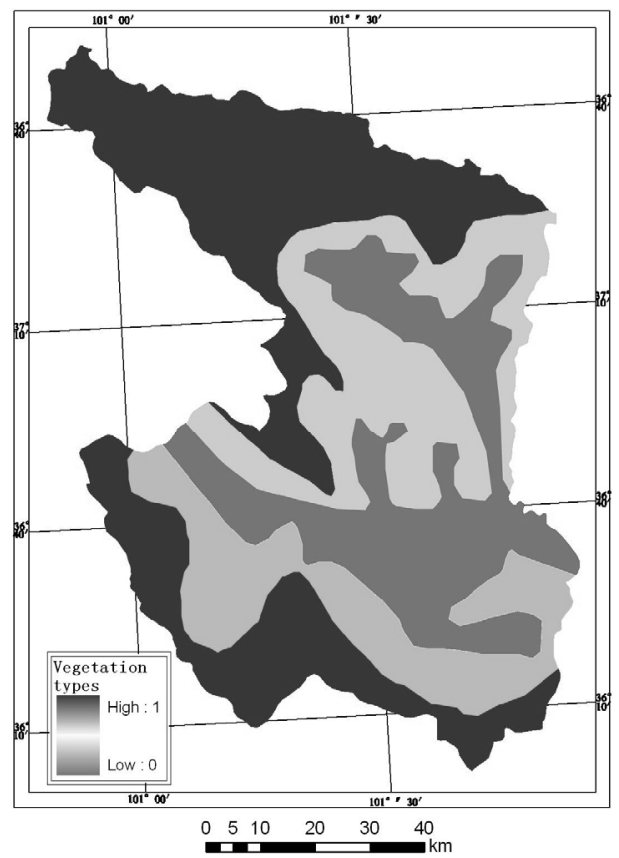

c)

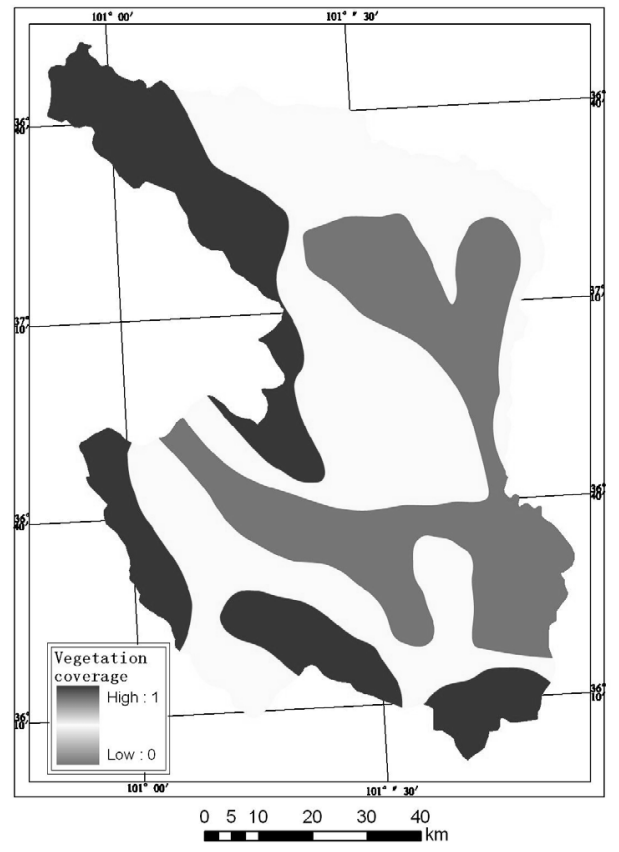

b)

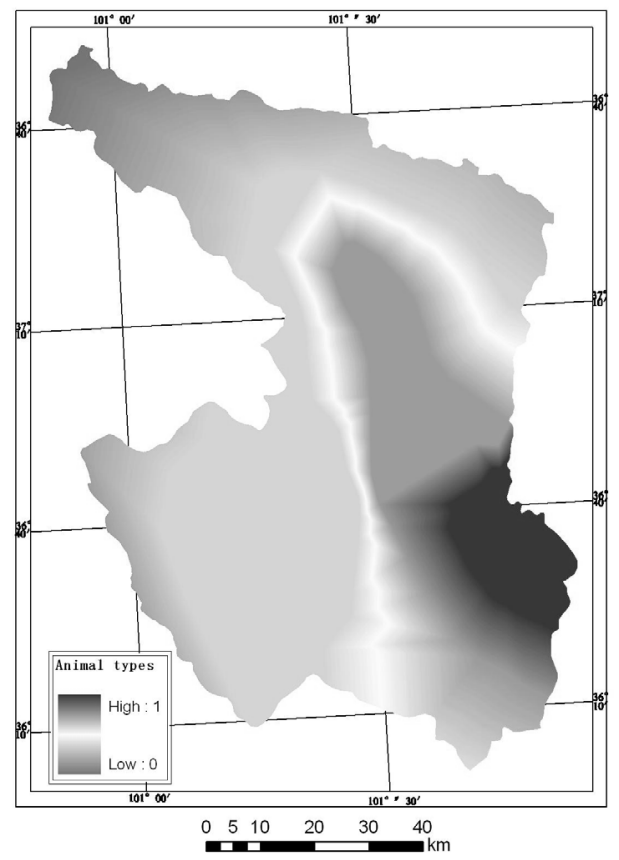

d)

Figure 6. Assessment results of biosphere factors 


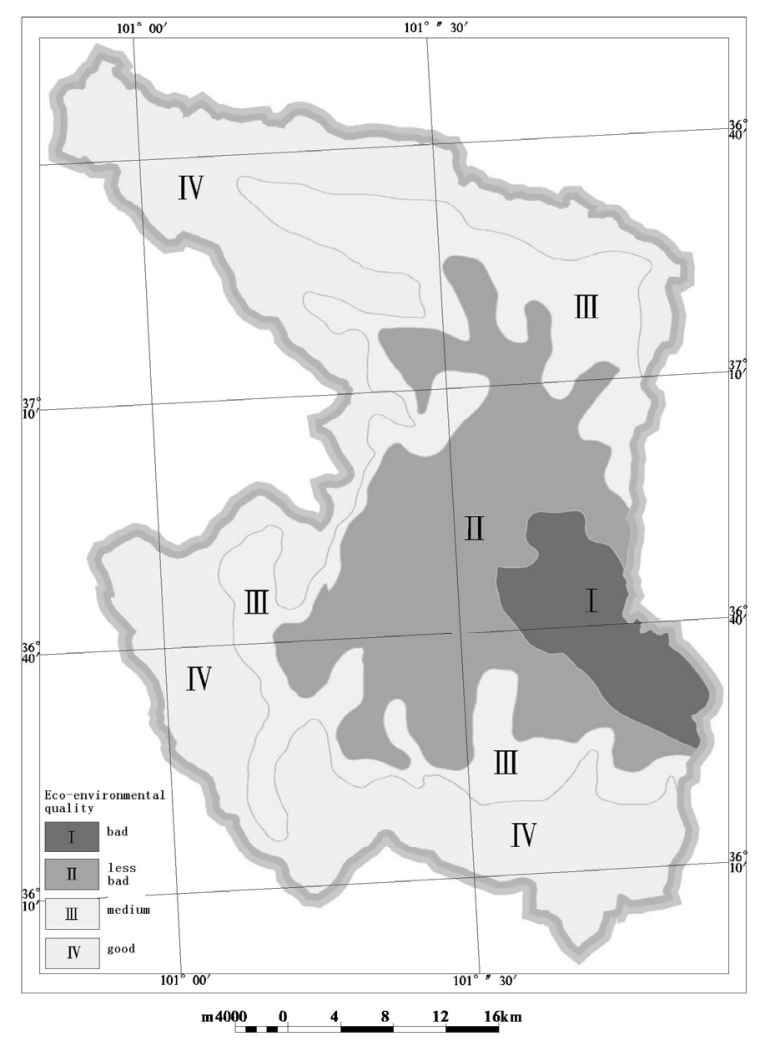

Figure 7. Eco-environmental quality assessment of Xining area 